\title{
The comparison of mental health between athlete and non-athlete teachers in schools of education in Gilan province
}

\begin{abstract}
Goals: Mental health is one of the most important aspects of society health assessment and plays an important role in the dynamism and efficiency of each society. The purpose of this study was to compare mental health between athlete and non-athlete teachers in schools of education in Gilan province.
\end{abstract}

Methodology: This causal-comparative study was conducted on the descriptiveanalysis method. The statistical sample of this study was 600 male and female physical education teachers and male and female non-physical education teachers in schools of Gilan province. The instrument of this study was included Goldberg's General Health Questionnaire-28 (GHQ-28). The collected data were classified by descriptive statistical methods and were analyzed by independent T-test.

Results: The score mean of mental health in physical education teachers was $20.25 \%$ and the score mean of mental health in non-physical education teachers was $31.11 \%$. The results showed that there was a significant difference between two groups in depression, social dysfunction and anxiety subscales $(\mathrm{P}<0.05)$, but there was no significant difference between two groups in the somatic symptoms subscale $(\mathrm{P}>0.05)$.

Conclusion: Physical activities seem to be necessary as an appropriate, easy and inexpensive approach to increase mental health among teachers. Authorities can lead the society towards physical and mental health through the planning in the field of exercise and physical activity for teachers and the encouragement them to sports activities.

Keywords: gilan province, mental health, athlete and non-athlete teachers, education
Volume 2 Issue I - 2018

\author{
Vahid Bakhshalipour,' Bisotoon Azizi, ${ }^{2}$ Siavash \\ Khodaparast Sareshkeh ${ }^{3}$ \\ 'Sama technical and vocational training college, Islamic Azad \\ University, Iran \\ ${ }^{2}$ Department of Physical Education, Islamic Azad University, Iran \\ ${ }^{3}$ Department of Physical Education and Sport Science, Islamic \\ Azad University, Iran
}

Correspondence: Vahid Bakhshalipour, Sama technical and vocational training college, Islamic Azad University, Iran, Email vahidbakhshalipour@yahoo.com

Received: October 03, 2017 | Published: January 24, 2018

\section{Introduction}

Many studies emphasize on the health of communities. ${ }^{1,2}$ Health is recognized as one of the main prerequisites for social welfare systems. The health and welfare systems in the world promote their goals from the provision of health cares to a creation of a healthy community. ${ }^{3}$ We can found that the need for research in field of mental health and the survey of the effective factors on it is necessary with a look at the implications of urban lifestyle, apartment house and the mechanization of societies in recent years and its negative effects especially on individuals' mental health in a society and unresolved challenges. ${ }^{2,4}$ The participation in sport activities as a scientific approach can increase individuals' happiness and mental health. The various studies have shown that sport activities have psychological, emotional and social benefits in addition to physical benefits, for example, the reduction of anxiety and depression, the increasing of sleep duration and better social relationships have been reported in different studies. ${ }^{4,5}$ The rapid development of technology that has emerged in the last three decades of the 20th century has caused that millions of people have realized that the coordination with these changes that is a feature of the present era is increasingly painful and this acceleration affects the depths of the soul in addition to the body and the process of adaptation against continuous changes needs the body's energy consumption. ${ }^{6,7}$ If a human has not enough calm to draw lost physical and personal resources and exposed to these severe psychological pressures repeatedly, the process of destruction will begin and then he/she will be sensitive to the disease especially psychosomatic diseases. ${ }^{8}$ Therefore, a human finds him/herself in anxiety without justification, fatigue, depression or feelings of dissatisfaction and aimless and he/ she will hurt to relationships between individuals in the same way. ${ }^{8}$ One of the ways that psychologists introduce for the prevention and treatment of mental health problems is the role of physical activities in mental health, because the industrialization of societies and the reduction of physical activity in individuals have been revealed the need of sport more than ever and an extensive attention has been paid to exercise especially the role of exercise in psychological issues. ${ }^{9,10}$ Previously, the public perception about the relationship between exercise and mental health was that sports activities are beneficial for physical health, but today, attention is paid to this fact that sport can be effective on the mental health promotion in addition to physical health. ${ }^{6}$ But today, the exercise functions in all aspects of a human's body are approved by researchers, so that researchers believe that regular motor and sport activities are one of good health habits or health promotion behaviors that have positive effects on human's health and quality of life and reduce the psychological and physical disorders and increase mental health. ${ }^{11,12}$ Studies show the importance of this study and since teachers are educators of all the strata of society so this study conducted for teachers in schools of education in Gilan province. According to the stated content, we hope that this study be effective for the promotion of individuals' mental health in the community especially for teachers. This will help to identify effective factors on the improvement of mental health. Therefore, the 
purpose of this study was to compare mental health between athlete and non-athlete teachers in schools of education in Gilan province.

\section{Material and methods}

This causal-comparative study was conducted on the descriptiveanalysis method.

\section{Participants}

The statistical population of this study was all male and female physical education and non-physical education teachers in schools of Gilan province. The statistical sample of this study was included 600 teachers that they were selected by randomized multi-stage cluster sampling. The criteria of subjects' selection were including no depression and psychological problems and the lack of important problems such as mental disorders in the questionnaire completion.

\section{Instruments and tasks}

The instruments of this study were included Goldberg's General Health Questionnaire-28 (GHQ-28) and a demographic questionnaire. The original form of the General Health Questionnaire-28 was designed by Goldberg and Hillier in 1970 and its validity and reliability have been reviewed several times. The average validity of this questionnaire is 0.84 by Kalman and Wilson's GHQ28 questionnaire and the average of its feature is 0.89 . The validity of whole questionnaire was reported 0.95 by Goldberg and Williams. This questionnaire has been used in many countries as a reliable instrument in the field of mental health and it has an acceptable validity in the field of research. Goldberg's General Health Questionnaire measures four categories of nonpsychotic disorders such as somatic symptoms, anxiety and insomnia, social dysfunction and depression. Likert's scoring method (0 to 3 ) was used for each case. The scoring criteria were the intensity of the evaluated symptoms and a higher score indicated a high intensity of the symptoms. According to this, a person with a score of 23 and lower score was considered as a healthy person and with a score of 24 and higher score was considered as suspected person who had a disorder.

\section{Procedure}

Science this causal-comparative study was conducted on the descriptive-analysis method, so there was not a possible to create the training and the training protocol and a special intervention in subjects. Only the criteria that were for athlete and non-athlete teachers' recognition were considered. Therefore, athlete teachers were individuals who participated at least 3 times a week in sports programs and activities and non-athlete teachers were individuals who did not have any physical activity or who their activities were limited to daily routine of life and education by the study of scientific contents and training methods for the consideration of the desired indicators for being athlete or not in this study,

\section{Data analysis}

The collected data were classified by descriptive statistical methods and were analyzed by independent T-test. The SPSS software (version $21)$ was used for data analysis $(\alpha \leq 0.05)$.

\section{Results}

The subjects' age mean for male physical education teachers was $43 \pm 6$ and for female teachers was $40 \pm 4$ in this study. The age distribution of this study was $43.2 \%$ in the age range (30-39) and $38.3 \%$ in the age range (40-50) and $11.1 \%$ in the age range (51-60) and $7.4 \%$ in less than 30 years. 223 people of subjects' total number had a physical education and sport science certificate and 377 people had no physical education and sport science certificate. Also in terms of educational level $44.3 \%$ of the subjects had a bachelor's degree, $48.2 \%$ of them had a master's degree and $7.5 \%$ were $\mathrm{PhD}$ students. In terms of gender of the physical education group, male teachers were $58.91 \%$ and female teachers were $41.09 \%$. Also, non-physical education male teachers were $61.6 \%$ and female non-physical education teachers were $38.4 \%$ in the non-physical education group. According to the results of this study, the mean of general health score among physical education teachers was $20.56 \%$ that $30.12 \%$ of them were abnormal and $69.88 \%$ of them were normal in terms of mental health. The mean of obtained score from general health questionnaires among non-physical education teachers was $31.11 \%$ that $49.16 \%$ of them were abnormal and $50.84 \%$ of them were normal. The results in the (Table 1) (Table 2) showed that there was a significant different between male and female physical education and non-physical education teachers in the depression subscale $(\mathrm{P}<0.05)$. Also, there are a significant difference between male and female physical education and non-physical education teachers in social dysfunction $(\mathrm{P}<0.05)$, but it was not observed a significant difference between two groups in somatic symptoms subscale $(\mathrm{P}>0.05)$. In addition to, there was a significant difference between male and female physical education and non-physical education teachers in the anxiety subscale $(\mathrm{P}<0.05)$. In general, there was a significant difference between male and female physical education and non-physical education teachers in mental health (Table 3).

Table I The results of independent T-test in the relationship with male teachers' mental health subscales

\begin{tabular}{|c|c|c|c|}
\hline \multirow[t]{2}{*}{$\begin{array}{l}\text { Mental health } \\
\text { subscales }\end{array}$} & $\begin{array}{l}\text { Male physical education teachers } \\
(N=136)\end{array}$ & $\begin{array}{l}\text { Male non-physical education teachers } \\
(\mathrm{N}=2 \mid 3)\end{array}$ & \multirow[t]{2}{*}{ P-value } \\
\hline & Mean士SD & Mean士SD & \\
\hline Depression & $2.11 \pm 1.18$ & $5.10 \pm 3.18$ & 0.02 \\
\hline Social dysfunction & $7.89 \pm 4.11$ & $11.91 \pm 6.11$ & 0.04 \\
\hline Somatic symptoms & $5.40 \pm 3.13$ & $5.39 \pm 4.42$ & 0.051 \\
\hline Anxiety & $4.11 \pm 3.46$ & $6.91 \pm 3.61$ & 0.01 \\
\hline Total & $|9.5| \pm 8.36$ & $29.31 \pm 9.11$ & 0.03 \\
\hline
\end{tabular}


Table 2 The results of independent T-test in the relationship with female teachers' mental health subscales

\begin{tabular}{|c|c|c|c|}
\hline \multirow[t]{2}{*}{$\begin{array}{l}\text { Mental health } \\
\text { subscales }\end{array}$} & $\begin{array}{l}\text { Male physical education } \\
\text { teachers }(\mathrm{N}=64)\end{array}$ & $\begin{array}{l}\text { Male non-physical education } \\
\text { teachers }(\mathrm{N}=\mid 15)\end{array}$ & \multirow[t]{2}{*}{ P-value } \\
\hline & Mean $\pm S D$ & Mean $\pm S D$ & \\
\hline Depression & $3.10 \pm 1.71$ & $5.8 I \pm 3.4 I$ & 0 \\
\hline Social dysfunction & $8.81 \pm 4.19$ & $|4.9| \pm 6.96$ & 0.01 \\
\hline Somatic symptoms & $5.61 \pm 3.79$ & $6.11 \pm 4.18$ & 0.051 \\
\hline Anxiety & $4.10 \pm 3.61$ & $6.10 \pm 3.30$ & 0.01 \\
\hline Total & $21.62 \pm 10.11$ & $32.93 \pm 10.20$ & 0.02 \\
\hline
\end{tabular}

Table 3 The results of independent T-test in the relationship with athlete and non-athlete teachers' mental health subscales

\begin{tabular}{|c|c|c|c|}
\hline \multirow[t]{2}{*}{$\begin{array}{l}\text { Mental health } \\
\text { subscales }\end{array}$} & $\begin{array}{l}\text { Physical education } \\
\text { teachers }(N=200)\end{array}$ & $\begin{array}{l}\text { Non-physical education } \\
\text { teachers }(\mathrm{N}=328)\end{array}$ & \multirow[t]{2}{*}{ P-value } \\
\hline & Mean士SD & Mean $\pm S D$ & \\
\hline Depression & $2610 \pm 1.39$ & $5.845 \pm 3.49$ & 0 \\
\hline Social dysfunction & $8.35 \pm 5.61$ & $|3.4| \pm 6.32$ & 0.01 \\
\hline Somatic symptoms & $5.50 \pm 2.63$ & $5.75 \pm 4.62$ & 0.051 \\
\hline Anxiety & $4.10 \pm 2.18$ & $6.50 \pm 3.60$ & 0.01 \\
\hline Total & $20.56 \pm 9.10$ & $31.11 \pm 9.52$ & 0.02 \\
\hline
\end{tabular}

\section{Discussion and conclusion}

The purpose of this study was to compare mental health between athlete and non-athlete teachers in schools of education in Gilan province. The results of this study showed that there was a significant difference between physical education and non-physical education teachers in mental health $(\mathrm{P}<0.05)$. Physical activity has always been recognized as the core of healthy behaviors over the years and has been associated with a reduction in related-lifestyle chronic illnesses. According to researchers report, regular physical activity as an effective and non-pharmacological intervention leads to many physiological and psychological benefits. ${ }^{6,11}$ It means that physical education teachers had a higher mental health score in comparison with non-physical education teachers. This result is consistent with the results of Hamer; $;$ Rass \& Hayes $;{ }^{13}$ Anonymous; ${ }^{14}$ Narimani et al. ${ }^{15}$ Ahmadi \& Pirhayti, ${ }^{16}$ Nariman's ${ }^{17}$ study. According to these results, it can be said that the stressful work environment and the environment without facilities play a role in the reduction of teachers' social dysfunction performance and reduce these members' general health. Studies show that physical activity and exercise can be effective in the reduction of depression and anxiety. The regular exercise training is also associated with the reduction of depression. ${ }^{13}$ Exercise is closely related to mental health, especially the prevention of mental disorders in addition to as a valuable tool for the maintaining of physical health. Exercise reduces anxiety and depression and increases individuals' self-esteem of. ${ }^{7}$ The individual's responses in educational environments are considered in the process of the stresses increasing. In spite of orders for the maintaining of health and wellbeing, today's human is observing significant changes in the reduction of physical activity and a variety of mental and physical illnesses by this reduction due to technological advances and the development of urbanization phenomenon. However, exercise can be considered as a desirable and efficient instrument to maintain survival, physical and mental health and a preventative factor of diseases. ${ }^{11}$ The functions and effects of exercise are not limited to the human's physical aspects. Exercise is also a factor for the release of mental stresses and tensions and coping with threatening crises of life. Exercise is the training of realistic thinking and the avoidance of mentalist thinking. Thus, the development of sports participation among the various classes reflects the degree of orientation system and rationality of a society in the current situation and it also means the cognitive, emotional and social development in members of that society. The society deprivation of individual and social effects and functions of exercise is certainly an irreparable harm that affects not only the current generation, but also many generations. ${ }^{4,6,12}$ Physical trainings are directly effective in the modification of mood through the release of endorphins and the reduction of cortisol (stress hormone). Therefore, it is known that exercise can deliver more endorphin and serotonin to the body and be maintained for a long time in the body and leads to the promotion of mental health. ${ }^{18}$ The endorphins levels increase during exercise, so athletes feel a sense of pleasure and relaxation after exercises. Physical activity is effective on cognitive and emotional functions of the brain such as memory and learning through the effectiveness on the secretion of endorphins, norepinephrine, catecholamine, serotonin and other neurotransmitters of the brain. ${ }^{19}$ Researchers' survey has shown that exercise can increase blood flow, oxygen and brain glucose and as a result the optimal function of the brain. ${ }^{20,21}$ Undoubtedly, the establishment of a healthy and happy society depends on the physical and mental health of the members in the society and needs to efforts of healthy, efficient and thoughtful human forces. In this regard, the human and specialist resources in education that often have acceptable scientific and practical knowledge and abilities need to be able to overcome threatening factors of general health by the management of their organizations. ${ }^{8,14}$ Otherwise, the reduction of 
their capability will be inevitable. In this regard, the highest harm will be for students who are trained and the educational goals will encounter with serious problems. On the other hand, teachers will be aware of harmful problems and resources in their profession with the cognition of these factors and will use coping methods to deal with its undesirable effects. ${ }^{13}$ In general, according to the results of this study and earlier studies, it can be inferred that healthy and happy teachers are a source for the growth and development of societies. For this reason, we need to create the conditions to have healthy teachers. since one of the ways for the achievement of this is to provide the favorable conditions and facilities for the tendency and promotion of exercise and physical activity among teachers, so it is suggested that authorities and experts pay attention to the planning for teachers exercise and physical activity. Authorities and experts will lead the community towards physical and mental health if they encourage teachers to participate in sports activities, because a community, an organization, or even a family can only pass the way of development and evolution when has healthy, valuable and good individuals.

\section{Acknowledgements}

We thank all subjects who helped us in this study.

\section{Conflict of interest}

Authors declare that there is no conflict of interest.

\section{References}

1. Frumkin H. Healthy places exploring the evidence. Am J Public Health, 2003;93(9):1451-1456.

2. Maller C, Townsend M, Pryor A, et al. Healthy nature healthy people: contact with nature' as an upstream health promotion intervention for populations. Health Promot Int. 2006;21(1):45-54.

3. Cabral M, Astbury J. Women`s mental health: an evidence based review. Mental health determinants and populations department of mental health and substance dependence world health organization Geneva. World Health Organization, Geneva, Switzerland; 2000. p. 95.

4. Nilsson K, Sangster M, Konijnendijk CC. Introduction. In: Nilsson K, et al. editor. Forests, trees and human health. Springer, Netherlands; 2011. p. $1-19$.

5. Ahmadi T, Pirhayti S. The effect of the selected exercise on male students` happiness and mental health. Procedia-Social and Behaviral Sciences. 2012;46:2702-2705.

6. Ahmadi E, Alizadeh SS, Shirmohamadzadeh M. Experimental study of the effect of exercise on mental health of students. Tabriz University of Teacher Education. 1385;29(19-28):19-29.
7. Esfahani N. Effect of exercise on mental health of students in 4 dimensions Somatic Symptoms. Anxiety/Insomnia; Social Dysfunction; Severe Depression. 2002;78-85.

8. Nasab SMHM, Taghavi SMR, Mohammadi N. Optimism and Stress Appraisal: Evaluation of Two Theoretical Models in Prediction of Psychological Adjustment. J Kerman Uni Med Sci. 2006;13(2):111-120.

9. Blanchard C, Rodgers W, Spence J, et al. Feeling state responses to acute exercise of high and low intensity. J Sci Med Sport. 2001;4(1):8-30.

10. Feyer A, Herbison P, Williamson A, et al. The role of physical and psychological factors in occupational low back pain: a prospective cohort study. Occup Environ Med. 2000;57(2):116-120.

11. Fuentes J, Díaz C. Analysis of heart rate during a tennis training session and its relationship with heart-healthy index. J Sport Health Res. 2010;2(1):26-34.

12. Hoyt LT, Lansdale CPL, Dade TW, et al. Positive youth, healthy adults: Does positive well-being in adolescence predict better perceived health and fewer risky health behaviors in young adulthood? $J$ Adolesc Health Jan. 2012;50(1):66-73.

13. Hamer M, Stamatakis E, Steptoe A. Dose response relationship between physical activity and health: The Scottish health survey. Br J Sports Med. 2008;43(14):1111-1114.

14. Ross CE, Hayes D. Exercise and psychological well- being in the community. Am J Epidemiol.2008;127(4):762-771.

15. Anonymous R. Burnout in Texas Division 4A and 5A High School Athletic Trainers Form a Reversal Theory Perspective. 2005;76(1):A100.

16. Nariman A, Akbarzadeh M, Hamzeh M. Evaluation of general health in medical students of AJA University of Medical Sciences, 2009. HBI Journals. 2010;8(1):49-55.

17. Narimani M, Ariapouran S, Ahari SS. The comparison of self-discovery and general health in individual and team athletes and non-athletes. Journal of Pouyesh 2007;6(3):179-184.

18. Imayama I, Alfano CM, Kong A, et al. Dietary weight loss and exercise interventions effects on quality of life in overweight/obese postmenopausal women: a randomized controlled trial. Int J Behav Nutr Phys Act. 2011;8:118.

19. Elavasky JR, Auley E. Physical activity enhances long-term quality of life in older adults. Ann Behave Med. 2005;30(2):138-145.

20. Luoto R, Moilanen J, Heinonen R, et al. Effect of aerobic training on hot flushes and quality of life-a randomized controlled trial. Annals of Medicine. 2012;44(6):616-626.

21. Martinsen EW. Physical activity in the prevention and treatment of anxiety and depression. Nord J Psychiat. 2008;47:25-29. 